\title{
RUMO AO JUDICIÁRIO: breves considerações psicanalíticas e históricas sobre a servidão ao Direito e ao Poder Judiciário
}

\author{
TOWARDS JUDICIARY: brief psychoanalyst and historical \\ considerations about voluntary subjection to the Law and Judiciary.
}

\author{
HACIA EL PODER JUDICIAL: breves consideraciones históricas \\ y psicoanalíticas del servilismo a la ley y a la judicatura
}

João Carlos da Cunha Moura
Mônica Teresa Costa Sousa

\begin{abstract}
Resumo: Análise do discurso jurídico, seus mecanismos de saber-poder e de como se determina essa emissão de discursos no sentido de submeter os sujeitos às instâncias da Regra e da Lei e, por fim, do Direito e do Poder Judiciário. Para tanto, o aspecto metodológico e o marco teórico se baseiam na dialética e na psicanálise, considerando o desejo dos indivíduos de atravessar as instituições e por estas serem atravessados, num jogo cíclico de legitimação de condutas.
\end{abstract}

Palavras-chave: Regra. Lei. Direito. Poder Judiciário.

\begin{abstract}
This paper aboard the theme of juridical discourse, its mechanisms of know-power and how it is determinate this emission of discourses in a way to submit subjects to the instances of the Rule and the Commandment, and then, the Law and Judiciary Power. For this, the methodological and the premise are based upon the dialectics and psychoanalysis, considering the desire of individuals in crossing the institutions and be crossed by the institutions, in a cyclical game in order to legitimate its behaviors.
\end{abstract}

Keywords: Rule. Commandment. Lew. Judiciary.

Resumen: : El texto aquí presentado trata el tema del discurso jurídico, sus mecanismos de poder y conocimientos técnicos para determinar el tema del discurso con el fin de someter el asunto a las instancias de la Regla y de la Ley y, por último, la Ley y el Poder Judicial. Por tanto, el aspecto teórico y metodológico basado en dialéctica y el psicoanálisis, teniendo en cuenta el deseo de las personas a cruzar las instituciones y de ser cruzados por éstas, en un juego de legitimación del comportamiento cíclico.

Palabras clave: Regla. Estado de Derecho. Ley. Poder Judicial.

\section{INTRODUÇÃO}

Quando um conflito se instaura em uma relação é da ânsia e desejo das pessoas que este seja resolvido o quanto antes. A paz, a ordem, enfim a tranquilidade só chega quando não existem conflitos a serem dirimidos. Como são problemáticas as relações, a Regra atua. Moral, Ética, Religião são alguns dos mecanismos que podem ser evocados para dissolver a demanda. No entanto, com os novos tipos de relações e na ordem do arcabouço de regras que o Estado de Direito começou a adotar, alguns conflitos não conseguem ser solucionados pelas próprias pessoas, estas procuram uma instituição "neutra" e "imparcial" para resolver esses conflitos. Nesse momento o Poder Judiciário entra em cena.

O trabalho aqui apresentado pretende investigar por que o Judiciário é acionado a resolver problemas que até certo ponto não lhe dizem respeito por não se tratarem strictu sensu de uma regra jurídica.

Primeiramente traz-se à discussão a ideia de Regra em uma noção de retidão, isto é, a Regra aqui é prevista como uma criação de determinada instância da ordem social. Desse ponto, a Regra é o principal limite estabelecido, um círculo fronteiriço que se coloca em todas as instâncias da vida. O espaço que ela abarca pode se tornar a totalidade da existência e sob a Regra (em forma de leis, normas etc.) os conflitos devem ser colocados e analisados. As relações, conflitos, contratos etc. tudo precisa estar submisso a frases de autoria indeterminada para que haja algo de certeza e previsibilidade. A Regra atua sobre todas as relações - Regra, nesse contexto, equiparada às formas-condutas que se estipulam moral, social, juridicamente.

Logo, para entender o que se passa dentro da regra jurídica é necessário que se conheçam as técnicas de criação e perpetuação de

\footnotetext{
*Artigo recebido em agosto de 2013
}

Aprovado em outubro de 2013 
regras dentro do sistema social; quais são seus limites, seus discursos e seus sujeitos emissários e destinatários. A submissão é analisada diante da Regra e também como uma regra. Isto é, a Regra por si só já impõe outra regra: uma regra da submissão, da obediência.

Feito este escorço, a segunda fase do texto se deslinda de maneira a abarcar de que maneira a Regra transmuta-se em Lei, isto é, em uma regra jurídica. Ao acontecer a mudança do envoltório discursivo, uma regra, que pode ser de cunho estritamente privado, imprime um curso totalmente abarcado pelas instâncias públicas, em nome do Direito. Logo, aquela servidão ou submissão à Regra, torna-se servidão e submissão ao Direito, mecanismo que se pressupõe legítima para dirimir conflitos.

A última parte do texto busca investigar este espaço onde se lê o texto da Lei e se diz o Direito: o Poder Judiciário. Nesse sentido, busca observar como os sujeitos dessa instituição conseguem legitimá-la e também legitimarem-se a si próprios como aqueles que tem o poder de dizer o Direito.

O delineamento do texto está delimitado por uma leitura psicanalítica das ações dos sujeitos pertencentes às instituições. A questão que se apresenta está baseada em entender qual é o curso de formação da ordem dos discursos dogmáticos e jurídicos, gerando esse amor canônico e inquestionável pela Lei. Além disso, o tema é metodologicamente formado dentro de uma concepção dialética e histórica de análise, isto é, busca perceber de que forma as regras são obtidas, transmitidas e vinculadas aos sujeitos e o que os fazem ligar-se de tal forma a essas regras que a própria existência destas se basta.

\section{A SUBMISSÃO À REGRA (COMO REGRA)}

A Regra atua como um sistema externo, porém internalizado. De fora para dentro, atua nos indivíduos e estes a absorvem de maneira tal que as suas condutas necessitam de uma legitimidade já atribuída pela Regra. Legendre (1983, p. 21-22) afirma que o poder da Regra é justamente obscurecer os sujeitos e por consequência a própria sociedade, isto é, um discurso e uma maneira que a sociedade encontrou de se manter em equilíbrio. Os indivíduos, nesse sentido, não serão mostrados a si mesmos, estarão sempre cobertos por um véu Regrador, regente. Pois a sociedade (enquanto totalidade dos sujeitos em um espaço) não quer se descobrir, quer antes criar mecanismos de conduta que garantam a certeza de uma previsão. Controla-se o presente pelo discurso do futuro.

Kant (1985, p. 104) assevera que esse controle exercido por uma Regra necessariamente é emitido por um sujeito em posição legítima para tal. O controle é dado pela Regra para que os indivíduos não raciocinem, mas antes que se cumpra o que a Regra exige. Em outras palavras, não se deve raciocinar, apenas crer, pagar, cumprir. Enfim, deve-se apenas obedecer à Regra. O alerta a essa obediência desmedida que o filósofo faz referência não quer dizer que o sujeito livre para escolher é aquele que descumpre a Regra, mas aquele que a cumpre e eleva ao debate este cumprimento e a própria Regra em si.

Importante ressaltar que as Regras são discursos, isto é, elementos metanarrativos que se impõem como algo de extremo poder externo; desejo e vontade de se apropriar de tal poder. A Regra, assim, somente será obedecida se presentes todas as qualificações necessárias para o seu devido cumprimento e submissão: depende de quem diz e como se diz (FOUCAULT, 1996, p. 12). A principal Regra, a Regra par excellence, é a Regra da obediência.

Sempre no sentido de cima para baixo, da Regra se impondo por sobre as decisões e condutas dos indivíduos, são esses que acabam se formando pela Regra e não o contrário. A emancipação é apenas um simbolismo e na trilha do percurso da formação subjetiva essa subjugação disciplinar à Regra é estipulada de forma não violenta, senão com táticas especiais que se instalam nas relações imediatas entre os indivíduos. As instituições não surgem para sufocar o indivíduo, mas antes para que os próprios indivíduos se controlem a si mesmos (ARAÚJO, 2001, p. 114).

Por conta de uma "cultura de crises" (cíclicas, recorrentes e ao mesmo tempo permanentes), elevam-se os mais variados discursos de controle e submissão à Regra. A Regra da obediência, da submissão é o elemento chave para que as crises não afetem o caminho linear da sociedade, que precisa pensar e agir de modo uniforme, sem diligências que possam romper ou desestruturar essa unicidade. Mascaram-se as diferenças de concepções políticas em nome da unidade, despolitizando indivíduos e identidades. Nessa toada, o discurso motriz da obediência à Regra é o discurso do medo, este último emitido como a possibilidade de perder seu posto na sociedade, de não mais ser incluído ou de ser excluído a força, ficando à margem. Estar à margem da obediência é estar à margem da Regra. (SIMIONATTO, 1998, p. 58-59).

O medo se desenvolve no sentido de prolongar a fé. O discurso do medo não se resume necessariamente na inquietação perante um rompimento de paradigma, mas é o discurso de elevação da própria crença na Regra. Não há medo se não há desobediência à Regra. Não há o que temer se existe a fé (crença) na Regra. É assim que a Regra assemelha os indivíduos, garantindo por meio de discursos essa unicidade da sociedade. O medo surge não de si mesmo, mas da presença de um "outro" que não compartilha daquela crença na Regra que o "eu", estabelecido pelas instituições. 
Sabemos como foi perdido o Paraíso; devemos prestar a máxima atenção aos enunciados terroristas sobre o pecado atual, sobre a maneira como ele é cometido e sobre a medicina apropriada para curar seus efeitos: em toda a parte, a cada passo de tal percurso pode ser observado o combate do pecador contra seus demônios ou, como às vezes diz a Escola sobre esse ponto, o sofrimento de um paciente contra a verdade. (LEGENDRE, 1983, p. 137).

A subjetivação é então autocontida: formada a partir do dever de obediência à Regra, este institucionalizado e, para além, é internalizado e naturalizado. Por não se sentir parte de um todo e, mais, por se sentir como um ocupante de um espaço subjetivo já demarcado, o indivíduo se mantem inerte em seu locus, a saída desse espaço é o argumento de que se valem as instituições para identificar o desobediente. Assim, cultua-se o "quietismo": o indivíduo precisa obedecer à Regra para que a própria sociedade seja um todo harmonioso e coeso. (VIANNA, 1998, p. 190-191).

A obediência se coaduna com a criação de outra característica da submissão do sujeito em relação à Regra: a crença na Regra. A crença, na acepção de Legendre (1983, p. 23-24) é um termo elementar, necessário para o entendimento do controle que cria a sensação de liberdade do indivíduo submetido ao discurso emitido. O autor se refere a essa crença como o discurso da Regra que opera como uma ordem dogmática, cheia de simbolismos e fantasias. A reprodução dos símbolos e seu respectivo discurso de subordinação constituem os sujeitos. A Regra, independente do que seja e de como seja, precisa ser seguida e as pessoas têm isso em mente: se é Regra deve ser cumprida (moral, jurídica, social etc). Não há espaço fora da Regra para atuação: é o cárcere da mente e a fixação das condutas. O próprio "texto" da Regra, enquanto lei a ser obedecida, é que cria o inimigo e a crença na Regra, gera a obediência.

\begin{abstract}
A repetição extenuante dos signos, a obediência ao preceito e aos cânones da falta, a veneração das máscaras e esta perseverança do sujeito em sustentar a causa de seu objeto, todos esses elementos (essas instituitiones, eu diria de bom grado para reconhecer a densidade do vocabulário dos juristas romanos) definem uma constituição política da pessoa. O procedimento da análise dá forma textual a isso, quando o analisando sob o olhar que ele crê do Outro, arranca as palavras do seu corpo. Para cada um sua Lei específica, conforme a sua história, a sua apologética específica; para cada um sua versão particular da ciência do Poder, conforme a sua gramática e o léxico para dizê-la. (LEGENDRE, 1983, p. 23).
\end{abstract}

A Regra é o "dever ser", é como e onde deve ser dito, escrito, agido, enfim, é a Regra que dita como a vida deve ser vivida. Logo, se existe a Regra dispositiva que cerca a formação subjetiva do indivíduo, trilhar um caminho diverso é culpa do próprio sujeito. Conforme assinalado acima, a crença é tal na obediência que o próprio sujeito culpa-se por não "ser" no "dever ser". A vida humana, sob a obediência à Regra, é uma eterna reprodução de repressões (AGAMBEN, 1993, p. 39).

Porém, não seria esta mesma uma noção básica de uma vida harmoniosa entre os sujeitos? Não seria também a obediência uma maneira sustentável de prever as condutas e esperar que as pessoas ajam com o mínimo de previsibilidade?

Kant (1985, p. 108) responde a estas perguntas ensinando que de nada adianta uma solene estipulação das Regras do jogo (moral, cívico, social, jurídico etc.) se estas são impostas por uma força exterior (mesmo que simbólica). O filósofo concerne que as épocas históricas diferem entre si e que a imposição de Regras imutáveis viola o direito de liberdade e ação das novas pessoas que surgirão. É um ato contra a própria natureza humana. Assim, só é viável e aceitável uma Regra se esta parte dos próprios indivíduos do corpo social, unicamente se esse povo se submete a tal Regra, por consciência do esclarecimento (Aufklärung).

Entretanto, o sistema (pós)moderno de regulação de condutas impõe a Regra como um ente metafísico (mesmo que tangível). Dessa maneira, a crítica e a ação são desmobilizadas pelas barreiras e técnicas biopolíticas fomentadas pelas e nas instituições. Os sujeitos, enquanto espaços de subjetivação, já surgem com a pré-determinação indicada pela Regra. "Ser", em decorrência, é estar dentro do âmbito político da Regra, fixar-se dentro do sistema preparado para absorver o indivíduo. A aspiração individual nada mais é do que a aspiração da sociedade que se impõe sobre a vontade dos indivíduos, a qual a Regra já anteviu e instituiu como possibilidade de aspiração individual.

Segundo Marcuse (1973, p.18), é através dessa pré-determinação, que a sociedade torna-se unidimensional; pelo controle do tempo e espaço, meros aparelhos de governo dos corpos dos indivíduos. Unidimensional porque não aceita violações, ou melhor, questionamentos à Regra, não acata transformações que possam alterar o status quo. Contudo, é uma sociedade que, paradoxalmente, cria os mecanismos para tanto.

O comportamento aceitável/apropriado/recomendado de hoje pode ser considerado de maneira diferente amanhã à luz de circunstâncias alteradas ou de novos conhecimentos. Mas ao mesmo tempo, no que diz respeito a muitas transições diárias, as atividades são rotinizadas com sucesso através da recombinação no tempo e no espaço (GIDDENS, 2002, p. 126).

O discurso da obediência à Regra decorrente da crença, unidos, perfazem o caminho para outro elemento: a disciplina; que nada mais é do que a consequência lógica de uma série de discursos produzidos para o controle das ações dos indivíduos. A disciplina, bem como o discurso que caminha pari passu ao discurso do controle, é a profusão da natu- 
ralização da Regra. Disciplinado, o indivíduo naturaliza para si a Regra e se controla a si mesmo. Pelo controle domina inclusive as condutas alheias, observando a sua coadunância com a Regra (FOUCAULT, 1999, p. 45).

Essa visão institucionalizada, naturalizada é explicada por Legendre (1983, p. 78-80) dentro da perspectiva da reverência, uma espécie de conduta, fruto de todos os instrumentos de imposição da Regra. Necessário notar, segundo o autor, que a Regra é escrita, não fundamentalmente em textos escritos, mas em símbolos e sinais que dão voz ao dito como Regra. A forma de mostrar essa escrita é o que faz com que os sujeitos adotem ou não o discurso da Regra. Essa "reverência", então, é parte do ritual de assimilação. O que está em forma de escrita é desestruturado e apagado do seu conteúdo e contexto histórico. Nisso consiste a verdade dogmática: o indivíduo é subtraído da posição de crítica ou questionamento da Regra justamente porque esta é a-histórica, já formada em texto absoluto, dando sentido a si própria. Apenas um sujeito legitimado pode interpretá-la e até mesmo questioná-la. Ao indivíduo resta a submissão.

A Regra é uma prática epistêmica e não é dada a priori, mas é construída e ao mesmo tempo expropriada de sua circunstância contextual. Como é um discurso, a Regra é também um conjunto de todas as características da sociedade, não é fixa, mas dinâmica e circula entre os sujeitos, logo se for estanque sua efetiva força é destruída. O discurso da Regra, pela obediência, medo, crença etc. é a performance verbal que caracteriza o elemento que se quer trazer à tona. A função da Regra depende do sujeito da fala: aquele que emite o enunciado da Regra. Esse sujeito é colocado a um ponto de assimilação com a Regra, logo apenas ele pode falar, interpretar ou emitir a Regra (ARAÚJO, 2001, p. 98).

Pertencer à Regra e na Regra é assegurar poder, por mais paradoxal que possa parecer. Segundo Foucault (1995, p. 243), o que assegura o poder não é um modo de ação sobre os outros, e sim ter o controle de sua própria ação, isto é, a ação do indivíduo deve estar sob o véu da Regra. Assim, o empoderamento na ação é garantido quando o "outro" é o sujeito da ação e abrem-se as possibilidades daquelas condutas serem analisadas sob os discursos emitidos pela Regra. Quem percebe e observa tal ação do "outro" é aquele que está legitimado por estar "dentro da Regra" (indivíduo ou instituição).

A noção de autoridade é respeitada pelo "outro" (sujeito que está sendo observado sob o véu da Regra). É por isso que o poder é, de certa forma, tido como algo intocável e sagrado, segundo Legendre (1983, p. 119120). Hierarquicamente falando: sob a Regra, as instituições (e indivíduos legitimados por estas) estão no alto; à margem da Regra ou dentro da Regra os demais sempre abaixo destas instituições. Aliás, afirma o autor, é jus- tamente para isso que existe a/uma instituição: é o espaço do benefício para o sujeito que foge à Regra.

Logo, o fracasso em abarcar os fatos do mundo faz com que as instituições legitimem sua expansão; as dominações sob a Regra só se confirmam utilizando-se o argumento de uma dilatação para o efetivo cumprimento da promessa emitida pelos discursos da própria Regra: a realização do sujeito (DREYFUS; RABINOW, 1995, p.199-201).

Ainda de acordo com Legendre (1983, p. 143), a Regra tem a capacidade de fazer amar, não por si só, mas também pelo sujeito ou instituição que a impõe. A Regra é a senha que chama ao amor para a instituição ou sujeitos. Em um sentido de gostar, não é à Regra que se lança o sentimento de apreço, mas àqueles sujeitos (espaços vazios esperando por ocupação) e às instituições, pois são justamente essas figuras as legitimadas para emitir o perdão a partir da Regra.

A Regra não institui seu próprio cumprimento para o sujeito em ação, mas que ela própria seja caracterizada por uma via de dupla significação: deve-se atender a ela porque se faz o bem e, mais, deve-se impor a todos, pois evita o mal. Segundo Agamben (1993, p. 32), o bem é o lugar de apropriação do mal. Se é a Regra que faz o bem, o mal é que aquilo que a Regra não aceita, é aquele lugar em que o sujeito não é. Aqui não se recorre a éticas ou a abstrações, como é a Regra que define o que é bom ou mal, a ordem segue-se a essa instituição. O bem e o mal diante da Regra são a sua coadunância ou não com o dito da Regra.

A história da Regra é a história das instituições às quais as regras se vinculam. Conforme Manuel Hespanha (2005, p. 35), uma regra depende do como as instituições sociais se combinam para formar o discurso de respeito e obediência a uma regra desta instituição. Algumas dessas regras, segundo o autor, não pertencem a um espaço político mais alto da sociedade, mas antes pertencem primeiramente aos espaços privados de relações cotidianas. No século XIX, com a ideia de socialização e de que para esta ser coesa e harmônica necessitaria de instituições imanentes, perante as quais a ordem do Estado-nação tinha total controle, Hespanha (2005, p. 36) e também Foucault (1999, p. 46-47) consideram que as instituições tem o seu pequeno espaço de judicialização dos seus elementos e regras. Não é que as regras tenham em si um conteúdo jurídico próprio, mas passam por crivos, ou melhor, julgamentos de coadunação em suas microinstâncias

\section{DE LEI E DE DIREITO}

Ao adentrar o espaço subjetivo e internalizado pelo indivíduo, a Regra precisa de justificação para existir, bem como de uma forma de vislumbrar a sua efetiva aplicação. Como as instituições psíquicas como Moral e Ética 
podem ser aplicadas por qualquer sujeito a partir de suas convicções, é necessária uma instituição visível e superior que exija uma técnica apropriada para a aplicação da sanção (em sentido amplo: como censura, ou mesmo como premiação) pelo ato praticado. Esta instituição, nos Estados ocidentais, é o Direito. Conforme Legendre (1983, p. 185-186), esta forma de vislumbrar o Direito é uma moderna forma de substituir a religião enquanto aplicador dos castigos aos pecados, pois a Regra, agora transformada em Lei (jurídica e leiga) tem o poder de abarcar mais noções de subversão. Ainda de acordo com o jurista e psicanalista francês, a Lei se torna uma técnica de proteção dos sujeitos daquele espaço que ela delimita.

Agamben (2007, p. 65-66), ao analisar esse sentido de um Direito para o castigo, traz à tona uma concepção mais profunda do modelo Regrador que sai da religião para o uso comum dos homens. Afirma o autor que os juristas romanos tinham na concepção de profano, algo livre de nomes sagrados, restituído ao mundo humano. Assim, o Direito enquanto instituição seria uma prática ritualística de apropriação (ou devolução) das Regras religiosas (do latim religio, aquilo que separa homens e deuses). A Regra religiosa, agora, passa a Regra jurídica, pois profana, apropriada e restituída ao mundo humano e está apta a ser aplicada aos semelhantes.

Consigna-se importante um pequeno incurso histórico de formação do Direito ocidental e de suas relíquias sacras. René David (2002, p. 41) afirma que os séculos XII e XIII se delimitaram, no que diz respeito à transmissão do direito, dentro de uma perspectiva romana. Afirma o historiador que por não haver uma espécie de ordem jurídica coesa, melhor seria transmitir uma prática jurídica catalogada, glosada, tal como era o direito romano. Dessa maneira, era mais "fácil de conhecer", pois estavam encerradas em textos escritos. Além disso, o teor diferente do direito local, superava a noção apenas localista do Direito e o transformava em algo universalizável.

Os séculos XIV e XV foram marcados por uma espécie de subversão acadêmica desse ensino do Direito romano: procurava-se, segundo David (2002, p. 44), "reencontrar o sentido originário das leis romanas" e não apenas transmiti-las indistintamente. Foi uma ideia de repasse do entendimento de forma localizada, para dentro da sua sociedade, porém ainda de acordo com as glosas do direito romano.

Com a visão mais religiosa abarcada nos séculos XVI e XVII, o direito natural toma força e os indivíduos começam a se perceber como sujeitos de direitos. A razão que assimila a força jurídica do homem prescinde de que as regras só sejam aplicadas se estas foram devidamente aprovadas no exame da razão, isto é, não podem ser "contrárias à razão, à justiça, aos sentimentos e necessidades da sociedade" (HESPANHA, 2002, p.47).
Até então, as Escolas Jurídicas ainda não se preocupavam, segundo René David (2002, p. 48), com um direito mais amplo: um direito público que consagrasse os direitos dos próprios indivíduos. Porém, os séculos XVIII e XIX trouxeram a separação histórica e revolucionária que se apronta entre Igreja e Estado, fazem com que este último passe a estar investido da tarefa de proteção e salvação. Assim, seu meio de fazer legitimar-se é por intermédio da Lei. Legendre (1983, p. 179) assevera que não se trata de saber ou discutir se o clero perdeu sua capacidade interventiva - pois, segundo o autor, não a perdeu, apenas assumiu uma categoria supletiva nas indicações de quais as Regras serão "devolvidas" à instância humana.

Tal como qualquer Regra em sentido amplo, a Regra jurídica, em forma de Lei é a expressão de uma forma de dominação humana. Como é expressão de certeza e verdade, aparece também como uma forma de interpretação da própria justiça. Goyard-Fabre (1999, p. 188) aponta que os esquemas da Lei também são estereotipados, posto que são tão humanos quanto qualquer outro aspecto de qualquer Regra. O Direito, então, dado pelo Estado (o homem no poder) é uma restrição da vida. Além disso, a autora ainda afirma que o Direito, sob um discurso de aplicação irrestrita e igualitária da lei se torna uma forma legítima de regulação da vida, obscurecendo as diferenças entre os sujeitos nos atos sobre o qual atua.

Como sistema externo que é, o Direito precisa do seu simbolismo e ritualística para ser assimilado pela comunidade ao qual se quer impor. Conforme Foucault (1996), um discurso precisa necessariamente de formas de inscrição em sua ordem e também de uma forma ritual de emissão desse discurso.

Sendo assim, não é diferente com o discurso jurídico quando este é emitido através de códigos ou decisões que partem de sujeitos aptos para tal atividade. O Direito também é prática, uma prática de observação e obediência à autoridade instituída; não pelos homens, mas por um ente superior imaginário (um Pai imaginário), o que se dá então com o Direito, enquanto discurso e teoria, é a prática de fixação de legitimidade de um Poder (FOUCAULT, 1999; LEGENDRE, 1983).

O texto jurídico nada mais é do que a expiação da vontade dos sujeitos. Para Goyard-Fabre (1999, p. 197), o direito é na verdade o instrumento do Estado para a manutenção dos desejos das pessoas, instrumento esse que é dotado de uma paixão, a paixão pela Palavra. É também esse o sentido da ordem burocrática armada pelo Estado por meio do Direito que Pierre Legendre se refere:

Os textos que formam o corpo do Direito se apóiam uns aos outros para constituir e perpetuar as normas que tratam do adestramento de toda uma humanidade. Todos os acomodamentos, que da responsabilidade dos comentadores em vista desta cultura histórica, devem ser entendidos como implicando a 
perenidade da mensagem textual além das malversações ou dos arranjos da glosa segundo o tempo social (LEGENDRE, 1983, p. 82).

A Lei se confunde com o próprio Direito. Retorna-se então ao paradoxo da necessidade de certa regulação das condutas, analisado acima, ao que se recorre novamente a Kant (1985, p. 104-105), para quem este exercício de obediência não deve ser totalmente livre de raciocínio ou razão. Segundo o filósofo, as atitudes para com a Regra (jurídica inclusive) não devem ser feitas de forma passiva, mas com o que denomina esclarecimento (Aufklärung). O autor, então, dá um exemplo prático que é aplicado conforme a imposição de uma Regra jurídica: "o cidadão não pode se recusar a efetuar o pagamento dos impostos que sobre ele recaem; até mesmo a desaprovação impertinente dessas obrigações, se devem ser pagas por ele, pode ser castigada como um escândalo (que poderia causar uma desobediência geral). Exatamente, apesar disso, não age contrariamente ao dever de um cidadão se, como homem instruído, expõe publicamente suas ideias contra a inconveniência ou injustiça dessas imposições" (KANT, 1985, p. 106).

Contudo, como uma Regra que é, expressão totalitária por si só, as técnicas do Direito e da Lei irrompem no discurso e se legitimam de per si. É o mesmo discurso da obediência a qualquer Regra que o discurso do Direito se apropria. No texto jurídico e na Lei, se assentam o dizer soberano e a verdade absoluta das instituições (não apenas do edifício jurídico): o texto não é sozinho, é um encadeamento lógico de Regras jurídicas, no qual em seu ápice está uma Regra que determina a produção de outras Regras. A Lei é apagada do seu conteúdo histórico, é retirada e suspensa do seu tempo. Com esse tipo de afirmação Legendre (1985, p. 81) conclui que a Lei "desbota o universo da qual ela subtrai a história, ela despoja qualquer humano de pretensão de ter que dizer alguma coisa". O texto jurídico então gera a submissão, o medo e a crença da qual se valem as Regras para se manifestarem e serem seguidas. A Lei atua como uma zona de limite de expressões, ela impõe fronteiras interpretativas e esteriliza os conflitos, privando-os de seu caráter político.

Para Agostinho Ramalho Marques Neto (2010, p. 111), seguindo essa dialética do texto, a obediência à Regra jurídica é dada pela sua formalização lógica e sistemática e também pela própria positivação do Direito. Se anteriormente o direito não tinha voz, afirma o autor, na modernidade, com a estipulação e exigência textual rígida, o direito sai da "infância" e adentra um novo espaço, um espaço de declaração de direitos. A Lei escrita pelo Estado, também o vincula e a partir de então, sai-se da mera estipulação de deveres e passa também a declarar direitos. A partir disso, tem voz o Direito.
A instituição de Regras pela Lei é inclusive racional, na medida em que parte de um modelo de condutas para os quais os resultados já estão antevistos. Parte de um encadeamento lógico que sempre coloca a Lei como o instrumento pelo qual as condutas serão avaliadas. É puramente tecnicista e justamente essa racionalidade instrumental que funcionam como elementos de exclusão e de obscurecimento dos sujeitos (GOYARD-FABRE, 1999, p. 196).

O texto jurídico, desta maneira, é o gerenciamento das ilegalidades. Qualquer resistência (mesmo aquela a qual Kant se refere a partir do Aufklärung) é uma consequência própria das relações de poder. Frustrar o mandato de produzir um corpo dócil (FOUCAULT, 2010) não é o mesmo que invalidar esse mandato (da Lei), mas antes criar novas formas de manipulação para que ela atinja a totalidade dessa formação de condutas. A Lei, assim como qualquer Regra, legitima sua expansão pelos fracassos de abarcar as condutas humanas.

Já que está permeado de lógica, todo fator de resistência e/ou problematização acabam fadados às categorias jurídicas. Logo, se é resistência a algo racionalmente estipulado, a resistência e a subversão serão vistos como Mal; e como Regra que é, a Lei se define como o expurgador dos males. Exigir um direito, portanto, é estar sempre à margem do Direito.

\footnotetext{
As realidades políticas desse sistema ultracentralista (o sistema pontifício, reproduzido e camuflado pela dogmática do bom Estado) tem todas as chances de não serem mexidas: o dispositivo das ciências assume a responsabilidade da crítica da organização e canaliza qualquer subversão. Nada fica faltando, observemos, nem mesmo o estilo apologético para fazer desviar os trabalhos históricos sobre a Administração, tornando-os inofensivos e benignos (LEGENDRE, 19983, p. 192).
}

Nessa trilha, Lukács (2003, p. 475) avalia que o obstáculo para a ação de indivíduos ou grupos é justamente essa idealização política e científica da Lei e, por consequência, do Direito. Esses instrumentos - além de outras Regras - são dispositivos já arraigados e naturalizados. O Estado já aparece como ligação a um desenvolvimento histórico linear e a Lei é o seu principal elo, agregadora de desejos e repressões dos sujeitos na e da modernidade. A Lei se torna, então, a mercadoria do Estado de Direito: é com essa ficha que o Estado joga.

Continua o autor húngaro que a só possibilidade de transgressão de uma lei é o que garante a sua expansão e afirmação enquanto tal. A resistência à Lei, apenas por esta se apresentar enquanto tal e a preferência por agir à margem significa que a própria Lei atingiu seu sentido e influenciou as ações mesmo que contrárias ao texto (LUKÁCS, 2003, p.476). Pode parecer paradoxal, mas é o que Judith Butler e Pierre Legendre afirmam quando tratam de aproximar os transgresso- 
res como aqueles que frustram a Lei (BUTLER, 2001, p. 100) e os excomungados (LEGENDRE, 1983, p. 148). É que a Lei já definiu os sujeitos rebeldes, e estes já o são mesmo que não tenham praticado nenhum ato à margem. Como conclusão os autores assinalam que o discurso não se dirige para o "censurado" ou o "transgressor", mas para todos os outros indivíduos que veem aquela atitude ser punida.

A Lei, segundo Judith Butler (2001, p. 112113), cria sua própria versão oposta. É uma estratégia política do discurso jurídico para que o indivíduo se veja fixo e adequado ao seu texto. Uma reivindicação de um direito só pode ser efetivada desde que por sujeitos com uma identidade singular ofendida. Assim, o Direito além de normalizar condutas normaliza os próprios indivíduos, com estratégias políticas. Ainda segundo a autora, a Lei é ela própria erotizada, criando a sensação de que tudo a ela deve estar submetido.

Legendre (1983, p.26-27) enuncia esse sentido de Lei incluída em um novo topos, um modelo no qual a Lei institui-se como a própria transformação das condutas no plano fático. Segundo ele, o sistema jurídico serve como filtro que adestra para se amar o Poder. Quem segue a Lei está dentro dos mecanismos de poder e de certa forma apoderado, é um "dentro da lei" (legal). A Lei, então, instaura-se para todos sem distinção: é um universo perfeito e acabado que tem como destinatário o "eu", ao qual será aplicada uma censura para 0 ato que estiver "fora da lei" (ilegal).

Como atende a uma determinada política instituída, a Lei determina também o plano de vida dos sujeitos. O fracasso do indivíduo, enquanto articulador de uma identidade para si, perpassa pelas vias e limites da Lei. O comportamento humano é delimitado conforme o limite da lei. A Lei implica inclusive a tomada de posição do sujeito dentro da sociedade. O comportamento do homem esgota-se, portanto,
no cálculo correto das oportunidades desse curso
(cujas 'leis' ele já encontra 'prontas'), na habilidade
de evitar os 'acasos' perturbadores por meio da apli-
cação de dispositivos de proteção e medidas defensi-
vas (que se baseiam igualmente na consciência e na
aplicação de 'leis' semelhantes); muitas vezes, chega
até mesmo a se deter no cálculo das probabilidades
dos possíveis efeitos de tais 'leis', sem sequer tentar
intervir no próprio processo pela aplicação de outras
"leis". (LUKÁCS, 2003, p. 218)

A própria noção de Estado Democrático de direito ocupa um lugar essencial de ambivalência política e jurídica. A Lei, já assimilada como Direito nesse modelo de gestão de pessoas, é atravessada por uma série de determinações que devem ser seguidas, uma vez que sua expressão é a mesma expressão de legalidade e igualdade que pressupõe a juridicidade de qualquer relação. No modelo de Estado Democrático de Direto uma das funções principais da Lei é "enunciar direitos", isto é, garantir direitos como privilégios para os cidadãos que estão inseridos nesse espaço (ainda que não sejam suficientes os instrumentos para a eficácia dessas garantias (MARQUES NETO, 2010 p. 113).

O que se reflete então é o domínio de um "eu" absoluto, uma sociedade única e indivisível, com sujeitos sem diferenças todos iguais perante a lei (MARCUSE, 1973). Esse mito discursivo determina que a Lei "é uma ajuda para o sujeito", ela opera como a conduta perfeita, pois é sancionada democraticamente; é uma demanda que todos necessitam para sentirem-se empoderados (por estar dentro da lei) e também para refutar aqueles que não se coadunam com a instituição jurídica da Lei, que a tentam questioná-la e subvertê-la. Ao fim e ao cabo, "a Lei é investida de onipotência" (LEGENDRE, 1983, p. 113).

É dessa maneira que Lukács (2003, p. 466467), ao teorizar o Estado e o Direito como ideologias numa perspectiva marxista, afirma que legal e ilegal estão ligados ao Poder que o Estado exerce sobre outras instituições, inclusive sobre o Direito. Assim, uma lei de regulamentação qualquer não altera o plano fático se não se transmutam e/ou se afirmam novas perspectivas de aceitação desta lei. O Direito, enquanto aparelho de Estado, precisa sempre se basear na sua não problematização, mas antes na sua apenas aceitação.

Não é outra a perspectiva que Legendre (1983, p. 143) anuncia quando trata da propaganda dos governos no sentido de implantação de uma lei. As formas ritualísticas de apreensão dos conteúdos e de enunciação dos mesmos acabam por tanger a propaganda em um sentido único: o sentido da Fé, isto é, o sentido da crença. Em uma análise psicanalítica, nesse contexto, o autor afirma que o sujeito ao se deparar com uma lei propagandisticamente lógica e racional assimila uma segunda natureza: uma natureza que é externa a si e sob o pretexto de agir "dentro da lei", legalmente, legitimamente etc. tende a buscar a validez dos atos nessa natureza dada. Nesse sentido, Lukács (2003, p.474) reforça que a Lei existente é apenas um dado dentro do processo de formação dos sujeitos.

O pertencimento a uma classe "não querida" garante que o Direito estipule o medo: os sujeitos não querem estar presentes em tal categoria. A Lei impõe sua força pelo medo: o medo de não estar contribuindo para a coesão social, para a ordem das coisas como "devem ser". Ainda assim, afirma Simionatto (1998, p. 61), mesmo que em total sintonia com a Lei, podem ser negados direitos a quem não encontra determinadas condições materiais, sociais e/ou quando a própria ação de consagração de direitos pode alterar o status quo dos grupos dominantes.

Essa característica nada mais é do que a própria ideia de modulação das Regras por isso precisa a Lei de símbolos e estes são dados em forma de textos (que são a sua linguagem própria). A Lei é estabelecida por Regras jurídicas que ditam outras Regras jurídicas, para 
que nada fuja à ordem das coisas. O texto da Regra é essencial para que se garanta a modulação em relação ao tempo e ao espaço nos quais irá atuar. Por isso é necessária toda a ritualística e estética desses escritos, para uma organização desses símbolos. A Lei demanda certa imagem; tal imagem precisa ser vista - porém apenas por aqueles merecem "por direito" olhá-la (LEGENDRE, 1983, p. 157).

Esses sujeitos também já estão instituídos, conforme Agamben (2007, p. 55-56), muito por conta de onde parte a Lei, em sua expressão textual, o modelo de submissão, crença e medo se instalam. $\mathrm{O}$ autor do qual se emite a Lei não é um autor com estado civil, mas um ente abstrato (ainda que formado por indivíduos humanos). Com essa afirmativa do filósofo italiano, no sentido assinalado, pode-se entender que o autor-Estado se apropria dessa função de autor e que sanciona a si próprio o direito de autor, isto é, pode distinguir e selecionar os discursos que irá emitir enquanto impõe a Lei, esta também é uma prática epistêmica. Como dito acima, por ser Regra, a Lei não é dada a priori e o autor-Estado torna-se o próprio intérprete da sua autoria.

\section{RUMO AO JUDICIÁRIO}

O direito desnuda os fatos para o ambiente público, revela atos que dizem respeito à vida privada, assim precisa de um local específico para ser "analisado". Este espaço é o Tribunal, em nome de um poder: o Poder Judiciário. O Poder Judiciário se revela no Estado de Direito como a instituição social capaz (no sentido de ter legitimidade instituída) de dar solução aos conflitos a que as pessoas encontram no decorrer da vida. Nesse sentido, Hespanha (2005, p. 22) aponta que o sistema de decisões e as soluções jurídicas emitidas tem sua contingência dada em relação com o ambiente e o conflito para o qual deve atuar. Isto quer dizer que a Lei não se imporá na decisão judicial como um todo, mas de acordo com os participantes do conflito. É mesma a apologética a qual define também Pierre Legendre (1983, 23), e para tanto um Judiciário, imbuído de Poder é o espaço legítimo para defender as outras esferas (ou campos) do conhecimento e da vida para dirimir as possíveis lides.

Quem se envolve em um conflito tem no Tribunal (espaço físico do Poder Judiciário) o ambiente institucionalizado para desenvolver o seu aparato de relacionar "eu" e "outro" dentro do conflito. Nesse sentido o debate jurídico também é um debate político e como tal cada parte tenta trazer para esse plano o melhor do "eu" e o pior do "outro". O juiz, sujeito da fala do Judiciário, é um "outro" que julga. Barros (1997), nessa trilha, argumenta que as pessoas que se envolvem em um procedimento de lide judicial são expropriadas daquilo que sabem sobre si e sobre sua história. O Poder do Judiciário, sua força argumentativa e relação de empoderamento são tamanhas que os sujeitos são estranhados nos laudos, provas e documentos dos quais se revestem o processo em juízo.

Essa assepsia é necessária ao desenrolar da apologética do Direito e é no Poder Judiciário que ela se encontra em seu perfeito estado. O historiador e jurista português Manuel Hespanha (2005, p. 22) informa que essa pretensão de separação entre fatos e normas, se dá desde o século XIX, fruto de uma teria doutrinária que traz no seu núcleo uma ideologia dos juristas, que busca atravessar o direito apenas de conteúdo jurídico, não trazendo nenhuma outra forma de conhecimento - e ao que se percebe, aqueles outros conhecimentos que porventura aparecem no conflito, também são abarcados pelo discurso jurídico asséptico (AGAMBEN, 2002)

No mesmo sentido, Zafaronni (1995, p. 28) analisa que podem existir duas funções junto ao Poder Judiciário. Uma se relacionaria com o poder de legitimar condutas ou ações políticas de um indivíduo ou sujeito; a outra, que anda na via contrária, tenta assimilar todos os conflitos em bipartidos na ordem de estabelecer quem vence o debate, arbitrado pelo "juiz", esse censor/julgador dos conflitos da sociedade. Continua o autor argentino que as instituições já assimilaram essa assepsia e internalizaram, pois elas próprias e os indivíduos a cada uma ligada já "desconfiam das próprias tendências conservadoras do pensamento central e preferem, diretamente, manter-se submissos aos judiciários" (ZAFFARONI, 1995 , p. 28)

Tal submissão ao Judiciário é da mesma forma incluída na análise de Pierre Legendre (1983). Segundo o autor francês, o Judiciário (por meio dos seus sujeitos - os juristas) internalizam a necessidade de submissão aos seus discursos, é o outro lado dessa instituição, um lado paternalista e iluminado, que exige obediência, crença e medo. Obediência, por dar a última palavra; crença, pois é o espaço determinado para expedir a palavra; e medo de figurar entre os "ilegais" perante essa instituição. A Lei é, na direção dos modos de dominação weberiana destacados por Hespanha $(2005$, p. 23), o entendimento de que ela é ao mesmo tempo tradicional (porque está estabelecida há muito - senão desde sempre), carismática (porque inspirada por Deus) e racional (porque é eficiente).

\footnotetext{
O direito, em si mesmo, é já um sistema de legitimação, i.e., um sistema que fomenta a obediência daqueles cuja liberdade vai ser limitada pelas normas. $\mathrm{Na}$ verdade, o direito faz parte de um vasto leque de mecanismos voltados a construiir o consenso acerca da disciplina social (HESPANHA, 2005, p. 23-23).
}

Ocorre que o Poder Judiciário faz parte do mesmo Estado que institui a Lei por meio de um Legislativo, porém este atua na função de intérprete. Assim, o Judiciário também está sob o dever de obediência à Lei. Porém, "uma única interpretação, um único comentário da 
letra, faz calar as interpretações inferiores" (LEGENDRE, 1983, p. 87). A instituição "Poder Judiciário" serve também para controlar a modulação as regras jurídicas.

Esta ordem estatal e jurídica se alicerça no fato, acima analisado, de que a própria Lei se legitima por si só, pelo seu próprio texto. Não são problematizadas, apenas aceitas, e assim sendo o "próprio Estado não encontra dificuldades para controlar as transgressões em casos isolados, justamente porque em nenhum instante seu fundamento está sendo discutido", afirma Lukács (2003, p. 471-472).

Tal fato se dá pelo discurso que os próprios juristas emitem no sentido de obediência e respeito às tradições jurídicas. Segundo Hespanha (2005, p. 26-27), a própria história do Direito corrobora essa ideia de respeito e repetição de tradições, assimilando conteúdos e institutos sem que sejam ressignificados: os juristas romanos já eram conscientes das categorias jurídicas e haviam dado a estas sua formulação. Agamben (2007, p. 65) confirma a hipótese e amplia a ideia para a seara do político: as categorias jurídicas que antes eram associadas ao poder sagrado dos deuses, são transformadas em modelos humanos, e por isso agregam tal conteúdo às instituições da vida.

O que antes era uma faculdade do sujeito torna-se a partir disto uma lógica sistemática, que precisa de certa legitimação. Essa neutralização, esse aspecto distante da vida social é garantido pelo modelo do jurista construído academicamente como um imparcial, um neutro, cujas preocupações no caso concreto se limitam a abstrações sobre teorias das categorias envolvidas no conflito (HESPANHA, 2005, p. 32).

Assim, o Poder Judiciário é um enorme locus fechado que possui uma fechadura trancada e específica que abre seu conteúdo. O jurista, nessa concepção, atrelado ao saber acadêmico e neutral tem a chave. Legendre (1983, p. 87) afirma que essa chave é possibilitada àqueles sujeitos que tem o domínio do texto. Nesse sentido, a instituição detém a última palavra por meio dos seus sujeitos e como é uma instituição loteada por indivíduos de saber próprio e específico o Judiciário gera essa propaganda tranquilizadora, mascarada por um discurso de racionalidade que se quer sempre mostrar em primeiro plano.

Importa ressaltar que o Poder Judiciário antes de ser um Poder, é um ente investido de poder pelos sujeitos e pelo discurso. Em verdade, o Poder Judiciário não é dotado de poder, mas investido de poder (LEGENDRE, 1983, p. 119-120). Judith Butler (2001, p. 104), trilhando este caminho, afirma que uma instituição como a prisão, por exemplo, não está materializada até que se lhe invista poder. A materialização de uma instituição apenas se dá na medida de sua investidura com as relações de poder. A materialização do Poder Judiciário é o Tribunal.
O espaço do jurídico, dentro do Poder Judiciário, limita-se assim ao estabelecimento de uma ordem, discurso latente de um ordenamento a ser estipulado, porém na realidade tenta apenas dominar os indivíduos sob essa Lei e esse Direito.

Hannah Arendt (2011, p. 100 ss.) afirma que o Poder Judiciário é um dos aparelhos da burocracia estatal, uma forma de governo que as pessoas são privadas da liberdade política e do poder de ação. Ação que é, num sentido político, justamente a capacidade e a faculdade de juntar os semelhantes e aventurar sua história em algo diferente e novo. Entretanto, a burocracia instituída por meio de uma violência simbólica (ou mesmo física), sob um discurso de progresso e de promessa eficácia das instituições limita esta ação, sendo necessário um poder gerencial amplo e que cuide das aspirações das pessoas sob essa superioridade.

Esse progresso é assimilado como algo determinante e bom para a caminhada linear da sociedade. Logo, o próprio indivíduo vê as instituições e a elas delega suas faculdades, dando a elas poder sobre suas próprias decisões. Dentro das perspectivas e novas mudanças ao saber e pelos enunciados neoliberais, a sociedade se encontra em uma fase histórica que não mais precisa de si, de sua natureza e condição humanas. Hannah Arendt (2011, p. 107) afirma que o progresso e a possibilidade de novos horizontes fazem os indivíduos esquecerem suas capacidades possíveis, de alcançar algo verossímil e partir para uma aventura maior. O progresso científico é a ferramenta discursiva que tem leis próprias de enunciação. Os indivíduos deixam suas capacidades de lado, delegam aos doutos e cientistas e não são capazes de atender adequadamente as suas necessidades mais cotidianas.

Kant (1985) ao tratar do Aufklärung, vê a responsabilidade do próprio indivíduo que mesmo sabendo de suas capacidades e faculdades delega suas responsabilidades a entes institucionais. Com o novo sistema de produção que se instalava o filósofo afirma que são preguiça e covardia que fazem com que parte dos homens, mesmo esclarecidos, continue a delegar suas responsabilidades. Critica o autor:

\footnotetext{
Se tenho um livro que faz as vezes do meu entendimento, um diretor espiritual que por mim tem consciência, um médico que por mim decide a respeito de minha dieta etc. então não preciso esforçar-me eu mesmo. Não tenho necessidade de pensar, quando posso simplesmente pagar; outros se encarregarão em meu lugar dos negócios desagradáveis. (KANT, 1985, p. 104)
}

É da própria natureza de um conflito que este seja político antes de jurídico. O Judiciário é o espaço de esterilização política desses conflitos. É onde se suspendem os valores e identidades de cada parte para uma decisão justa e imparcial. Porém em uma situação de conflitos, pode-se tornar um problema de des- 
locamento e desmobilização social, justamente pela ideia de igualdade perante a lei que o discurso jurídico no Tribunal opera. (ZAFFARONI, 1995; SIMIONATTO, 1998, p. 49-50; VIANA, 1998, p.187).

De tal modo, se existem as leis que "enunciam direitos" (e o Direito em si) e se estas não estão sendo respeitadas, é preciso uma instituição e indivíduos legítimos e específicos para dizer estes direitos. É nesse sentido que Hespanha (2005, p. 47), ao tratar dos modelos jurídicos do século XIX, conclui que o processo e o tribunal eram tidos como construtores do modelo do mais fiel exercício do poder político. Chega o momento em que a própria vida se expressa em uma metáfora jurídica. É nessa mesma acepção que Agamben (2002, p.15) identifica que a política ocidental se transmuta em uma vida jurídica: quanto esta vida torna-se uma vida jurídica em si mesma.

Essa desmobilização e propriamente o deslocamento da capacidade e faculdade humanas podem ser articuladas junto com Legendre (1983, p. 32) e sua análise do texto jurídico como censura de condutas e atos. Segundo o autor francês, para ser lícita e a única possível, uma censura necessita que um poder sobre ela seja instituído e, então, deve ser adjudicada a outros que tenham tomado/assimilado o poder dos "pais", isto é, dos tecnocratas do sistema do Estado. Dessa maneira, esses sujeitos ("outros") garantem um direito de olhar sobre os outros sujeitos ("eu", "nós"). Ora, "se a Lei está no âmago do caso, se ela se impõe como vínculo e como leitura. Razão maior para transferir ao discurso da cultura a qualificação mais extrema, que pode expressar sem dificuldade a ideia da legitimidade absoluta" (LEGENDRE, 1983, p. 33).

Essa legitimidade do Poder Judiciário é garantida pelo modelo de ordem do discurso de que trata Foucault (1996) existe quem emita e existe para quem é emitido o discurso. A principal característica do jurista para abordar essa ordem discursiva é o ritual: série de práticas protocolares que identificam a legitimidade da fala do sujeito, pois as falas não se legitimam por si sós, mas por séries discursivas que fazem aparecer sua legitimidade. Conforme Legendre (1983, p.67), o Tribunal então é o espaço dessa prática ritualística do Direito, a prática de obedecer à instância onipotente (a Lei).

O juiz e o Judiciário acabam se tornando essa espécie de Pai dos indivíduos na medida em que utiliza o Poder que é fazer-se amar. Esse amor é dado a quem (sujeito) ou àquilo (instituição) que tem o, poder, ou pelo menos que se faz supor tê-lo. É realmente uma servidão voluntária. Da Regra à regra jurídica, até certo ponto, nada muda, apenas o invólucro do discurso. O núcleo que mantém a autoridade e a relação de poder continua o mesmo estabelecido: o sentido da dominação. O que fazem as instituições, sob um discurso emitido pelos textos jurídicos é a reprodução do fazer-crer, que não subverte em nenhuma instância suas funções de governar, reprimir e condicionar as condutas do ser humano. (PHILLIPI, 1994; LEGENDRE, 1983)

Zaffaroni (1995, p. 33) acredita que exista também, além dessa delegação de responsabilidades para o Judiciário, certa assunção dessas responsabilidades do próprio Judiciário. O jurista argentino entende que esse deslocamento é uma forma de satisfação do narcisismo dos juristas, que por sua formação acadêmica de um Direito que dá conta de todas as instâncias da vida, podem também dirimir debates políticos, angariando com isso uma espécie de capital social que os deixam em primeiro plano na atenção pública.

\section{CONSIDERAÇÕES FINAIS}

Observa-se que a Regra, enquanto instituição a ser obedecida, é ela própria maleável: ela modula o seu conteúdo de acordo com o momento, com a pessoa ou com o espaço. Importante ressaltar que a Regra se torna essencial e providencial quanto à forma e não quanto ao seu conteúdo. As próprias instituições mantem-se assim: sua verdade é sua forma. Por intermédio dessa ritualística que atravessa o indivíduo por discursos como medo, obediência, crença e reverência, impõe-se a totalidade da Regra e sua onipotência. Toda essa profusão e emaranhado de pequenas ordens formam a Regra em si. O sistema se previne contra possíveis falhas e incute na ordem o desvio que deverá ser punido ou censurado. Na regra religiosa, o pecado; na regra moral, a corrupção; na regra jurídica, o crime; e assim por diante.

A Lei é um sistema de práticas epistêmicas externo aos sujeitos, que os colocam em um passo demarcado e com resultado já antevisto. Em outras palavras, uma lei é apenas a forma jurídica de se apropriar das condutas dos indivíduos, fazendo com que se atue coordenadamente com um modelo que se pretendido. Tal modelo é açambarcado por um modelo social, político e econômico que necessita de um discurso ordeiro, que não pode correr os riscos de condutas não previstas.

Para o efetivo cumprimento das regras (e sua aceitação pacífica), as instituições emitem ordens que passam por uma ritualística e simbologia, no intuito de fazer o sujeito internalizar e naturalizar tais comportamentos. Assim, a regra da obediência sem limites à Regra deixa de ser uma política de imposição externa e passa a ser uma atitude própria que é emitida e reproduzida inclusive pelo próprio sujeito que se encontra sujeitado. A Regra transcorre instituições formais (que tem forma específica) tais como a família, a igreja, o tribunal etc. São essas instituições que fazem o jogo de ida e volta da Regra, que pertencem frente ao sujeito a um espaço mítico de aplicação do descumprimento da Regra. 
É necessário ter em mente que uma insituição é formada por sujeitos, logo esses são seus principais "inimigos". Como é o legítimo para aplicar e dizer a Regra dada, é possível que o sujeito atue de forma descontínua e modulada, o que pode gerar embaraços e perda de poder da instituição. É necessário, então, que a instituição tenha um emaranhado de normas decididas previamente, inclusive Regras de aplicação da Regra, assim mesmo, ad infinutum.

Com o advento do Estado (Democrático) de Direito e a separação das relações Igreja/ Estado, secularizara-se a Regra, e esta deve passar por uma instituição que autentique a punição ou a aprovação de determinada conduta perante os outros indivíduos. Se antes as condutas eram analisadas de acordo com a confissão dos atos frente a seus semeIhantes, com a complexidade ocorrida após as grandes mudanças de modelos econômicos e sociais o aspecto de "semelhança" entre indivíduos toma uma proporção maior, não mais apenas comunitário específico. As atitudes que as pessoas tomam passam a refletir em todo esse complexo emaranhado de pluralidade de sujeitos.

O Estado, então, divide suas atribuições e uma instância fica responsável pelo julgamento das tomadas de decisão humanas. O Judiciário se apresenta então como uma mão do Estado que é investido do poder de julgar. O Direito é o instrumento do Estado, e se transforma na ficha de jogo entre as pessoas. Em outras palavras, a Regra passa de privada a pública transmutando-se em Lei, encerrada em texto e interpretações.

Com suas formas próprias de atuação, o Estado mediante o espaço mitológico do Tribunal, prepara toda a cena para a efetiva legitimação deste ambiente como o espaço único de resolução dos conflitos que surgem na sociedade. Se os direitos estão enunciados (dados) nessas normas, é necessário que exista uma instância externa e superior aos indivíduos que analise as possíveis violações a esses direitos. Tal espaço, dentro de formas, normas e ritualística processual, terminam por esterilizar o conflito que a ele se apresenta.

É essa assepsia que também contribui para a internalização do Direito como um totalizador, que assimila todas as condutas possíveis dentro da sociedade. Quando se percebe uma conduta fora desse emaranhado de leis e que se definem por si sós, o sistema jurídico expande sua instituição; e é legítima essa expansão, pois já assimilado pelos sujeitos que o Direito é a instância máxima de proteção e condução da ordem social. Sob o discurso de igualdade perante a lei, termina por encobrir as diferenças, abarcando também as possibilidades de resistência contra determinada norma.

Com a nova dimensão dessa sociedade acomodada que observa as instituições como meras prestadoras de serviço, os indivíduos buscam por fim a seus conflitos não mais de forma política, senão antes enviando tais conflitos ao Poder Judiciário, que se torna o moldador das práticas, decisões e desejos humanos.

Entretanto, a legitimidade de poder-saber não é dada apenas pela sociedade que envia seus anseios ao Poder Judiciário, mas também pelos sujeitos presentes nestes espaços demarcados que também acabam por assumir esta responsabilidade, tanto pela suposta erudição adquirida nos bancos das Universidades quanto pela necessidade de se mostrar como guia paterno de toda a sociedade. Tais sujeitos são também responsáveis pela acomodação da sociedade frente a conflitos próprios e políticos, pois tendem a ostentar um compromisso com o estabelecimento da ordem. Das suas decisões parecem sair toda a tranquilidade que a sociedade anseia.

É necessário certo cuidado na tomada de decisões através de assepsias da política das deliberações jurídicas: a decisão pura e simples adequada apenas à anestésica solução do conflito não leva em conta as possíveis consequências de sua decisão. Essa assunção de responsabilidade do Judiciário encerra, ao fim e ao cabo, um envio das responsabilidades aos outros Poderes.

\section{REFERENCIAS}

AGAMBEN, Giorgio. A comunidade que vem. Lisboa: Presença, 1993.

Homo sacer: o poder soberano e a

viada nua. Belo Horizont: UFMG, 2002.

Profanações. São Paulo: Boitempo, 2007

ARAÚJO, Inês Lacerda. Foucault e a crítica do sujeito. Curitiba: UFPR, 2001.

ARENDT, Hannah. Sobre a violência. Rio de Janeiro: Civilização Brasileira, 2011.

BARROS, Fernanda Otoni de.

Interdisciplinaridade, uma visita ao Tribunal de Família pelo olhar da psicanálise. In: PEREIRA, Rodrigo da Cunha (Org). Direito de Família contemporâneo. Belo Horizonte: Del Rey, 1997. p. 781-835.

BUTLER, Judith. Mecanismos psíquicos del poder: teoria sobre la sujeción. Madrid: Cátedra, 2001.

DAVID, René. Os grandes sistemas do direito contemporâneo. São Paulo: Martins Fontes, 2002.

DREYFUS, Herbert; RABINOW, Paul. Michel

Foucault, uma trajetória filosófica: para 
além do estruturalismo e da hermenêutica. Rio de Janeiro: Forense Universitária, 1995. FOUCAULT, Michel. O sujeito e o poder. In: DREYFUS, Herbert; RABINOW, Paul. Michel Foucault, uma trajetória filosófica: para além do estruturalismo e da hermenêutica. Rio de Janeiro: Forense Universitária, 1995. p. 231-249.

Loyola. 1996.

A ordem do discurso. São Paulo:

. Em defesa da sociedade. São

Paulo: Martins Fontes, 1999.

- Vigiar e Punir. Tradução Raquel

Ramalhete. 29.ed. Petrópolis: Vozes, 2004.

- O governo de si e dos outros:

curso no Collège de France (1982-1983).

São Paulo: Martins Fontes, 2010.

GIDDENS, Anthony. Modernidade e identidade. Rio de Janeiro: Jorge Zahar, 2002.

GOYARD-FABRE, Simone. Os princípios filosóficos do direito político moderno. São Paulo: Martins fontes, 1999.

HESPANHA, António Manuel. Cultura Jurídica: uma síntese de um milênio. Florianópolis: Fundação Boiteux, 2005.

KANT, Immanuel. Textos seletos: edição bilíngüe. Trad. Raimundo Vier e Floriano de Sousa Fernandes. Petrópolis: [s.n], 1985.

LEGENDRE, Pierre. O Amor de censor: ensaio sobre a ordem dogmática. Rio de
Janeiro: Forense Universitária, 1983.

LUKÁCS, Gyorgy. História e consciência de classe: estudos sobre a dialética marxista. São Paulo: Martins Fontes, 2003.

MARCUSE, Herbert. A ideologia da sociedade industrial: o homem unidimensional. Rio de Janeiro: Zahar Editores, 1973.

MARQUES NETO, Agostinho Ramalho. Neoliberalismo: o declínio do Direito. In: RUIBIO, David Sánchez et al. (Org.). Direitos humanos e globalização: fundamentos e possibilidades desde a teoria crítica. Porto Alegre: EDIPUCRS, 2010. Disponível em: <http://www.pucrs. br/orgaos/edipucrs/>. Acesso em: 10 nov. 2012.

PHILIPPI, Jeanine Nicolazzi. Direito e psicanálise: um diálogo com o pensamento de Pierre Legendre. Revista Alter Ágora. Florianópolis, n. 1, p. 64-72, maio 1994.

SIMIONATTO, Ivete. O social e o político em Gramsci. In: AGGIO, Alberto (Org.). Gramsci: a vitalidade de um pensamento. São Paulo: UNESP, 1998.

VIANNA, Luiz Wernck. Caminhos e descaminhos da revolução passiva à brasileira. In: AGGIO, Alberto (Org.). Gramsci: a vitalidade de um pensamento. São Paulo: UNESP, 1998.

ZAFFARONI, Eugenio Raul. Poder Judiciário: crise, acertos e desacertos. São Paulo:

Revista dos Tribunais. 